\title{
Developmentally regulated epitopes on a neurofilament protein visualized by monoclonal antibodies
}

\author{
Irmgard Thorey and Wilfried Seifert \\ Department of Neurobiologie, Max-Planck-Institut für Biophysikalische Chemie, Göttingen (F.R.G.)
}

(Accepted 18 April 1989)

Key words: Monoclonal antibody; Developmentally regulated antigen; Cytoskeleton; Neurofilament; Microheterogeneity

\begin{abstract}
Two monoclonal antibodies (mabs) which recognized the $68 \mathrm{kDa}$ subunit of the rat neurofilament triplet were isolated. In immunoblots with SDS-solubilized and reduced proteins, these mabs recognized their epitopes equally well in embryonic and in adult tissue. However, these epitopes were developmentally regulated in paraformaldehyde-fixed rat brain sections. They were abundant in all compartments of differentiating neurons, whereas in mature neurons their presence was markedly attenuated, with a moderate abundance in perikarya and larger dendrites and low concentrations in axons. Thus, a differential developmental modification, possibly involving the masking of an epitope, is demonstrated for the small neurofilament polypeptide in rat and monkey brain tissue.
\end{abstract}

\section{INTRODUCTION}

How can molecules be developmentally regulated in the nervous system? Some neuronal molecules are expressed transiently at a certain developmental stage $^{11,23,33,38}$. For the sake of simplicity, it can be assumed though, that most regulative mechanisms operate on the post-translational level, through modifications inducing conformational changes, masking sites, etc., in pre-existing neuronal proteins. This is particularly obvious for the structural proteins of the cytoskeleton: functional heterogeneity in its components enables the neuronal cytoskeleton to regulate the plasticity of neuronal connections. Not only can slightly heterogeneous isoforms create different functional states of the neuronal cytoskeleton during development, but they can also be distributed in a differential manner between spatial compartments, such as axons, dendrites, and cell bodies. Indeed, a variety of temporal and spatial modifications have been reported for the components of neuronal microtubules $s^{2.15 .31}$ and neurofilaments ${ }^{20,21,36,51}$.
In the two higher molecular weight proteins of the neurofilament triplet, NF-H and NF-M, functional heterogeneity is introduced by differential phosphorylation in different cellular compartments after the filament has been assembled from the subunits $^{24,35,45}$. Studies with monoclonal antibodies (mabs) that recognize phosphorylation-dependent epitopes showed that the neurofilament proteins in axons bear a larger number of $\mathrm{COOH}$-terminal phosphate groups than those in cell bodies ${ }^{26,27}$. 36.48 .49 . Moreover, the phosphorylation of the highest molecular weight neurofilament protein, NF-H, is developmentally controlled and takes place late in neuronal development, with the final establishment of the axonal growth pattern ${ }^{5.14,26}$. In peripheral nerve regeneration NF-H phosphorylation was shown to coincide with the return of normal nerve structure ${ }^{5}$; in chicken development it is concomitant with the functional maturation of the axons ${ }^{13}$.

Some heterogeneity in neurofilament proteins cannot be attributed to different phosphorylation states; e.g. a mab which was proven to be phosphorylation-independent recognized a developmen-

Correspondence: I. Thorey, Current address: Department of Physiology, 111 Giltner Hall, Michigan State University, East Lansing, MI 48824-1101, U.S.A. 
tally late isoform of NF-H in tissue sections and immunoblots ${ }^{52}$.

Previously, no microheterogeneity was reported for the distribution of the small neurofilament protein, NF-L. Although this protein is phosphorylated as well, there is no differential spatial distribution between the phosphorylated and the nonphosphorylated form ${ }^{36}$.

Here we now report a developmentally regulated epitope on the small neurofilament protein of mammalian CNS neurons which we identified with the mabs $\mathrm{A} 1$ and B3. In immunoblots our mabs recognized the $68 \mathrm{kDa}$ peptide of the neurofilament triplet. However, comparing the developmental time course of NF-L expression with our mabs and a commercially available mab to the same protein, NR4 (ref. 16), revealed differential regulation of epitopes.

We can show by immunohistochemical stains that NR4 reacts with an epitope that appears during the later stages of neuronal differentiation and gradually increases towards adult levels. Our antibodies, on the other hand, detect an epitope that reaches a maximal concentration in neurons while they differentiate, then decreases when the neurons have matured. Using immunoblotting technique, however, we were unable to show differences in the developmental time course of NF-L expression with our mabs and NR4.

Thus, we report two neurofilament epitopes which are regulated differently during development. Both of these epitopes are situated on the $68 \mathrm{kDa}$ neurofilament peptide and can be detected on this protein in Western blots. In intact neurofilaments, however, one of these epitopes is primarily available to antibody binding early during neuronal differentiation, while the other becomes accessible only at a later stage.

\section{MATERIALS AND METHODS}

\section{Antibodies}

Monoclonal antibodies against vimentin and glial fibrillary acidic protein (GFAP), as well as fluorescent and horseradish peroxidase- (HRP) conjugated second antibodies, were bought from Dakopatts, Hamburg, F.R.G. NR4 hybridoma supernatant was the kind gift of Dr. M. Osborn ${ }^{16}$, and affinity purified rabbit antiserum against NF-M was the kind gift of Dr. G. Shaw ${ }^{39}$.

\section{Production of antibodies}

Immunizations were carried out either by injecting mice with forebrain homogenates of day 20 chicken embryos or in vitro using the method of Luben and Mohler ${ }^{30}$ by incubating spleen cells for 4 days on top of a culture of rat hippocampal neurons. Immunization media contained an equal volume of thymocyte-conditioned medium and $20 \mu \mathrm{g} / \mathrm{ml}$ adjuvant peptide (Sigma). Fusions were carried out with the myeloma lines $\mathrm{FO}$ or $\mathrm{Sp} 2 / 0$ using $35 \%$ polyethylene glycol $/ 15 \%$ DMSO. Fused hybrids were selected by addition of $50 \mu \mathrm{M}$ hypoxanthine and $10 \mu \mathrm{M}$ azaserine to the growth medium. All hybridomas were recloned at least 3 times by limited dilution. Antibodies from culture supernatant were stored in

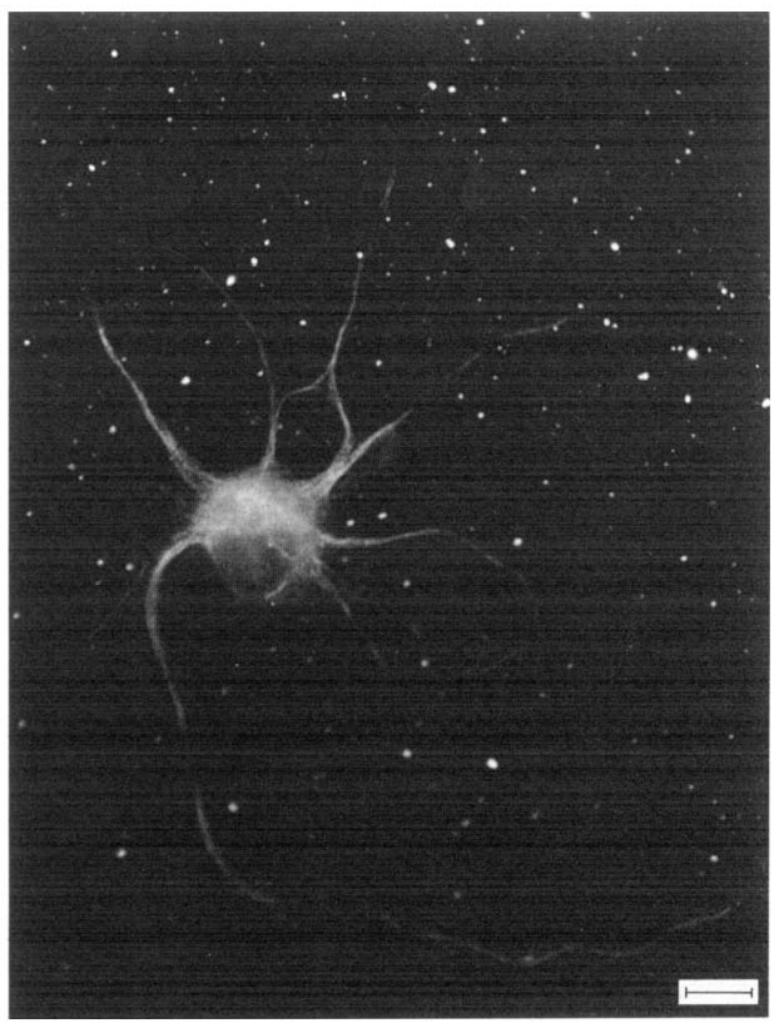

Fig. 1. A rat hippocampal neuron grown for 4 days in culture and stained with the mab Al after fixation with paraformaldehyde. A fibrillary, cytoskeletal staning pattern is visible in cell body, dendrites, and axon. An evenly distributed, punctate background stain on the coverslip occurred with all neurofilament antibodies. Bar $=10 \mu \mathrm{m}$. 

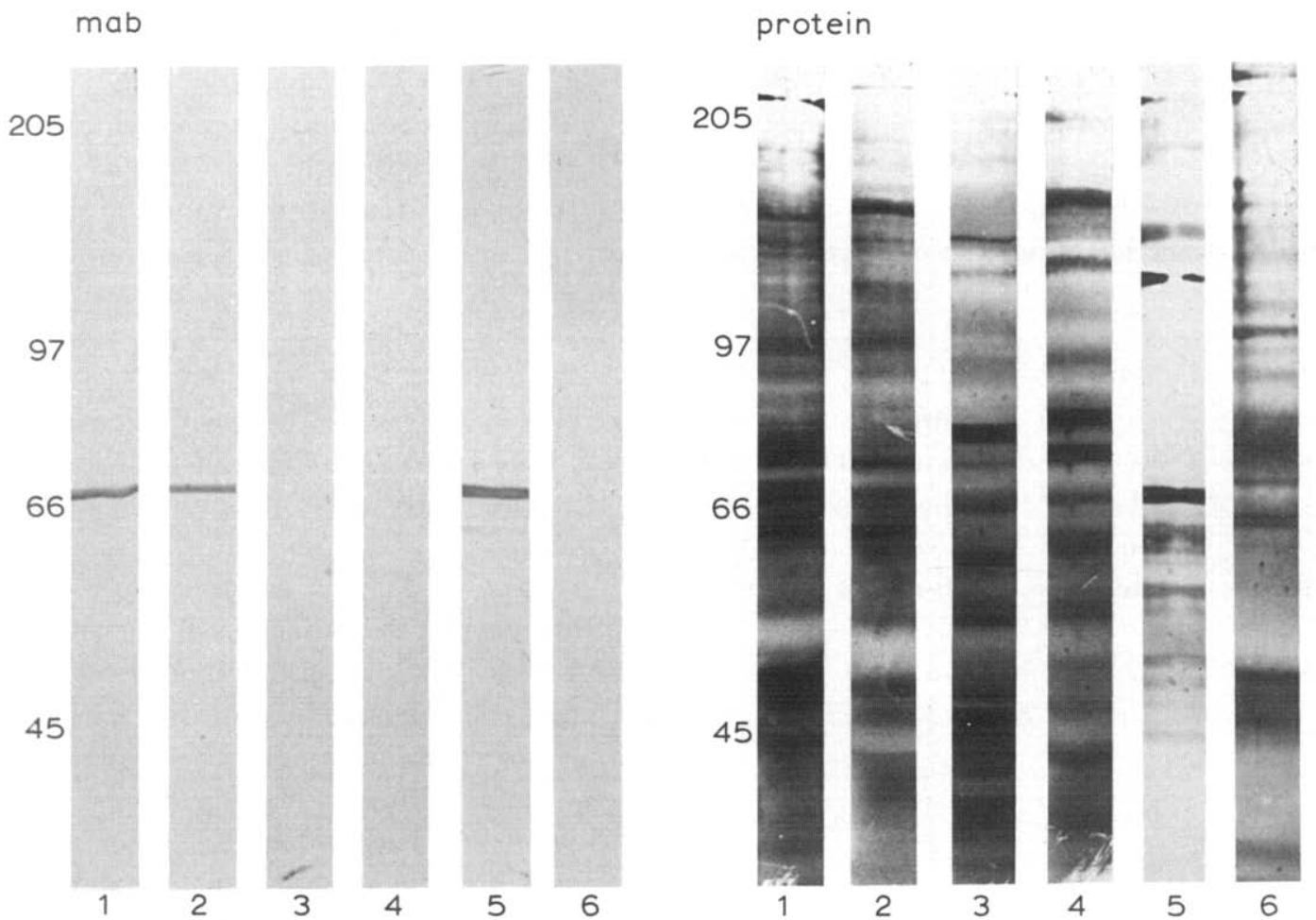

Fig. 2. Immunoblots of $7.5 \%$ SDS-polyacrylamide minigels which were stained with the mab B3 (left panel), or with India ink to visualize protein (right panel). Preparations from adult rats: lane 1, forebrain homogenate; lane 2, hippocampus homogenate; lane 3 , liver homogenate; lane 4, kidney homogenate; lane 5 , intermediate filament preparation from forebrain; lane 6 . microtubule preparation from forebrain. Lanes $1-4$ contained $50 \mu \mathrm{g}$ protein each, lanes 5 and 6 contained $25 \mu \mathrm{g}$ protein. The antigen has a molecular weight of about $70 \mathrm{kDa}$, and is only detectable in the two brain homogenates and in the intermediate filament preparation from brain, where it is enriched.

aliquots as ammonium sulphate $(50 \%)$ precipitates. Prior to use, the precipitates were pelleted by centrifugation, resuspended and dialyzed against PBS.

\section{Primary cell cultures}

Rat hippocampal cell cultures were prepared as described elsewhere ${ }^{3}$. Briefly, hippocampi were taken out at embryonic day 18, trypsinized and mechanically dissociated. Cells were plated onto polylysin-coated glass coverslips and grown serumfree either on a feeder layer of primary cortical astrocytes $^{34}$ or directly with N2 hormone cocktail ${ }^{6}$, with glucose content adjusted to $6 \mathrm{~g} / \mathrm{l}$.

\section{Tissue preparations}

For crude homogenates, tissues were doused in PBS and sonified. Intermediate filaments from forebrain were isolated by differential salt extraction ${ }^{17}$. Microtubule proteins from forebrain were prepared by in vitro assembly (one cycle) ${ }^{53}$. Protein content of preparations was measured according to Peterson ${ }^{37}$.

\section{Immunohistochemistry}

For immunofluorescent stains, cultured cells or slide-mounted cryostat sections of unfixed rat brain were fixed in a paraformaldehyde solution (either $4 \%$ for $30 \mathrm{~min}$, or $2 \%$ for $50 \mathrm{~min}$ ), and incubated with specific antibodies, followed by FITC-conjugated rabbit anti-mouse Ig antiserum diluted 1:50 (1 h; $37^{\circ} \mathrm{C}$ ).

For peroxidase-anti-peroxidase (PAP) stain, rat brains were perfused with $2 \%$ paraformaldehyde/ $0.1 \%$ glutaraldehyde for $50 \mathrm{~min}$, followed by $10 \%$ sucrose in Tris-buffered saline, left to settle in $30 \%$ sucrose, sectioned on a freezing microtome (40-60 $\mu \mathrm{m}$ ), and incubated floating in specific antibodies (4 $\mathrm{h} ; 37^{\circ} \mathrm{C}$ ), followed by rabbit anti-mouse Ig antiserum $\left(1: 25 ; 1 \mathrm{~h} ; 37^{\circ} \mathrm{C}\right)$ and mouse PAP complex $(1: 150 ; 1 \mathrm{~h}$ at room temperature). Color was devel- 
oped with diaminobenzidine. All sections were pretreated with $\mathrm{H}_{2} \mathrm{O}_{2}$ /methanol to destroy endogenous peroxidases. For each antibody, parallel samples preincubated with different concentrations of Triton $\mathrm{X}-100(0-0.5 \% ; 15 \mathrm{~min})$ were stained to control for effects due to incomplete permeabilization.

\section{SDS-PAGE and Immunoblots}

SDS-PAGE was carried out using the method of Laemmli ${ }^{25}$, and transferred to nitrocellulose using the method of Towbin ${ }^{47}$. Nitrocellulose was reacted with specific antibody $\left(\sim 2 \mathrm{~h} ; 37^{\circ} \mathrm{C}\right)$, then with peroxidase-conjugated rabbit anti-mouse Ig antise-

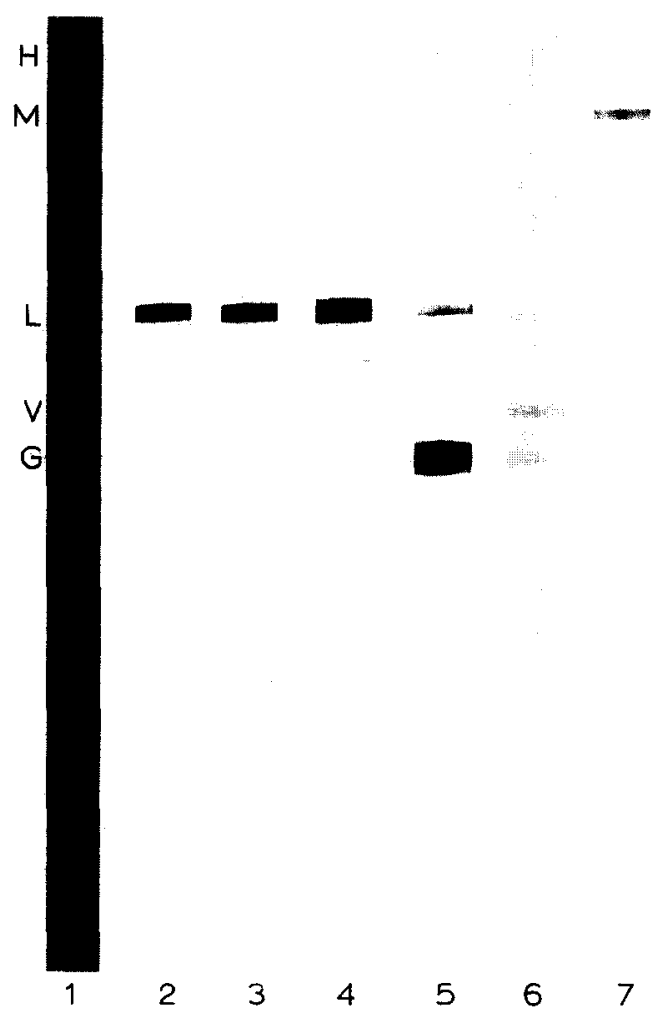

Fig. 3. Immunoblots of $10 \%$ SDS-polyacrylamide gels of intermediate filaments prepared from adult rat forebrain and stained with different antibodies. Indicated protein bands are: H, NF-H (210 kDa); M, NF-M (145 kDa); L, NF-L (68 kDa); $\mathrm{V}$, vimentin $(57 \mathrm{kDa})$; and $\mathrm{G}$, glial fibrillary acidic protein (51 $\mathrm{kDa}$ ). Lane 1, Coomassie Brilliant blue stain for protein; lane 2, mab A1; lane 3, mab B3; lane 4, mab NR4 against NF-L; lane 5, mab GA5 against glial fibrillary acidic protein (GFAP); lane 6 , mab V9 against vimentin; and lane 7 , polyclonal rabbit antiserum against NF-M. Our mabs, A1 and B3, and the mab against NF-L, NR4, recognize comigrating bands, whereas the antibodies against GFAP, vimentin, and NF-M recognize other bands. rum $\left(1: 150 ; 1 \mathrm{~h} ; 37^{\circ} \mathrm{C}\right)$. Color was developed with $0.5 \mathrm{mg} / \mathrm{ml}$ o-chloronaphtol.

A negative control was prepared for all immunological stains by incubating parallel samples with myeloma supernatant rather than specific antibody.

\section{RESULTS}

In several fusions, mabs were generated against embryonic chick forebrain and neonatal rat hippocampus. Twenty-six of the isolated hybridoma clones recognized neurons in paraformaldehyde-fixed frozen sections of the rat brain. To screen for developmentally regulated antigens, we compared antibody staining in sections from 7-day-old and adult rat brain: $40 \%$ of the antibodies stained the cell bodies of 7-day-old neocortical and hippocampal neurons significantly more intensely than in the adult rat brain, therefore recognizing antigens that are present in higher concentrations in differentiating neurons than in adult neurons. Six antibodies exhibited fibrillary staining patterns in cultured CNS neurons, suggesting an epitope located on one of the neuronal cytoskeletal filament systems (Fig. 1).

Two of these six antibodies, A1 (generated against chick) and B3 (generated against rat), were further characterized and were found to react similarly. Therefore, we will show figures only for monoclonal antibody B3.

Differences in staining intensities between cell bodies of differentiating and adult neurons were more pronounced when the tissue was fixed with paraformaldehyde, than when the tissue was fixed with methanol or acetone $\left(10 \mathrm{~min} ;-20^{\circ} \mathrm{C}\right)$. Therefore, paraformaldehyde was used routinely as fixative for all histological stains.

In immunoblots prepared from adult or 7-day-old forebrain or hippocampus homogenates, the 6 antibodies recognized a protein with a molecular weight of ca. $70 \mathrm{kDa}$. The antibodies were specific for CNS tissue, since they did not react with homogenized adult rat liver or kidney (Fig. 2). In order to determine whether the $70 \mathrm{kDa}$ band represents a microtubule or intermediate filament protein, these two cytoskeletal filament systems were purified from rat forebrain, using standard procedures (see Materials and Methods section). Both mabs recognized a band at $68 \mathrm{kDa}$ on immunoblots prepared from 

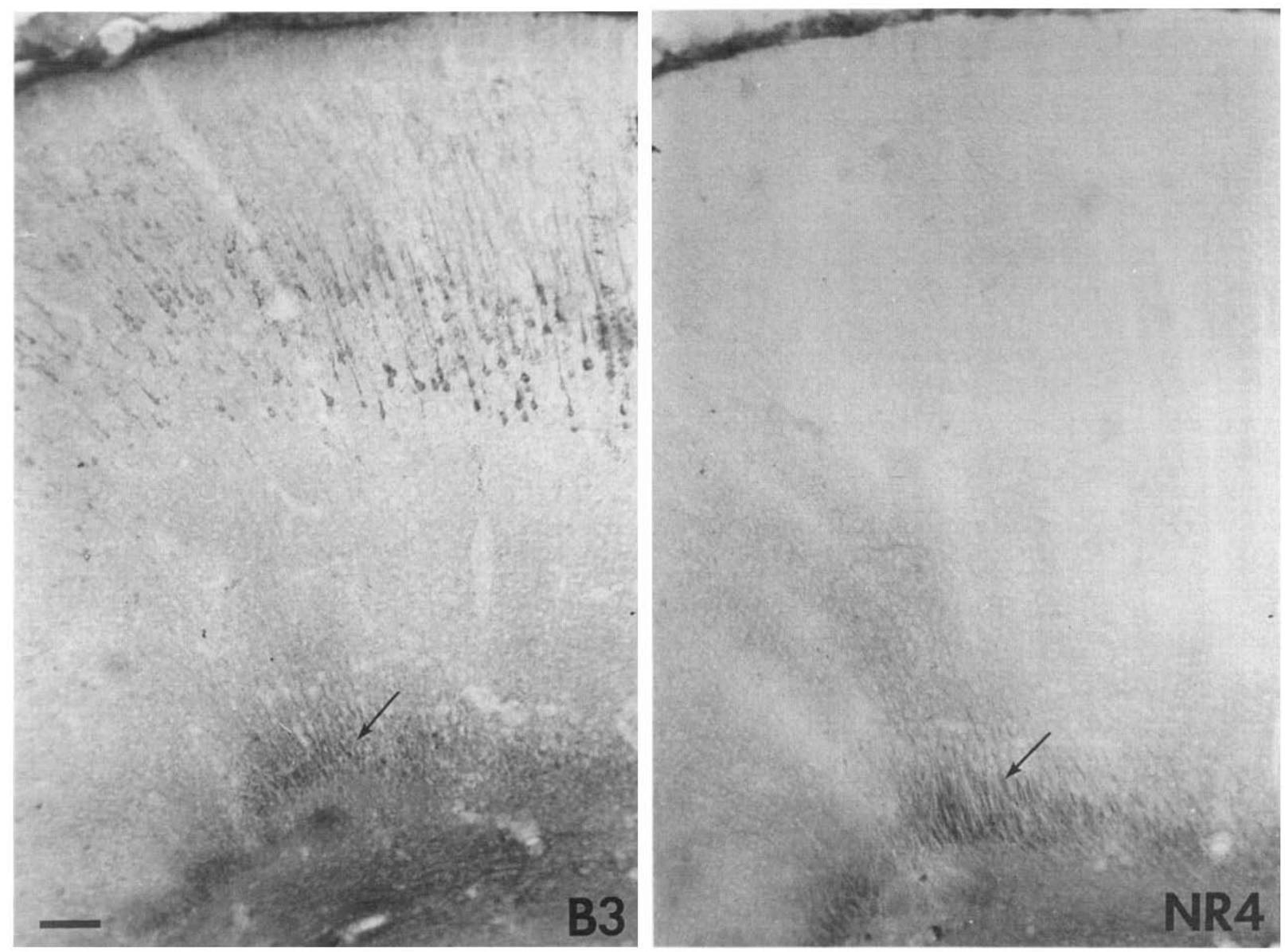

Fig. 4. B3 and NR4 neurofilament epitopes in the cerebral cortex of a 7-day-old rat. Both epitopes are present in fibers in the cortical white matter to a similar extent (arrows), but only the B3 epitope can be detected in cell bodies and outgrowing apical dendrites of differentiating neurons in the cortical plate. Non-specific staining of meninges occurred in all tissue sections. including negative controls. Bar $=0.1 \mathrm{~mm}$.

intermediate filaments. They did not react with immunoblots prepared from microtubule proteins (Fig. 2). Thus our antibodies appear to recognize the 68 kDa-peptide of the neurofilament triplet, NF-L.

Further evidence that these mabs bind to the 68 $\mathrm{kDa}$ neurofilament protein was obtained by reacting our antibodies along with several commercially available intermediate-filament antibodies, on adjacent immunoblot strips prepared from purified intermediate filament proteins (Fig. 3). As is shown by the Coomassie stain, this preparation contains only a few distinct protein bands. Our antibodies recognized the same band as the monoclonal antibody against NF-L, NR4 (ref. 16), whereas antibodies against vimentin, GFAP, and the $150 \mathrm{kDa}$ neurofilament component (NF-M) recognized other protein bands. These results strongly suggest that our mabs bind to an epitope on the $68 \mathrm{kDa}$ neurofilament protein.

We decided to investigate the developmental time course during which epitopes on the $68 \mathrm{kDa}$ neurofilament protein are expressed. We did so by perfusing rats of different ages with paraformaldehyde, preparing frozen microtome sections of the brain, and reacting them with our antibodies, as well as the NR4 antibody.

Fig. 4 shows a comparison between the neurofilament epitopes in the cortex of a 7-day-old rat. At this age cell bodies and dendritic processes of differentiating pyramidal cells in the developing cortical layers were strongly stained by B3. NR4, on the other hand, showed no detectable immunoreac- 

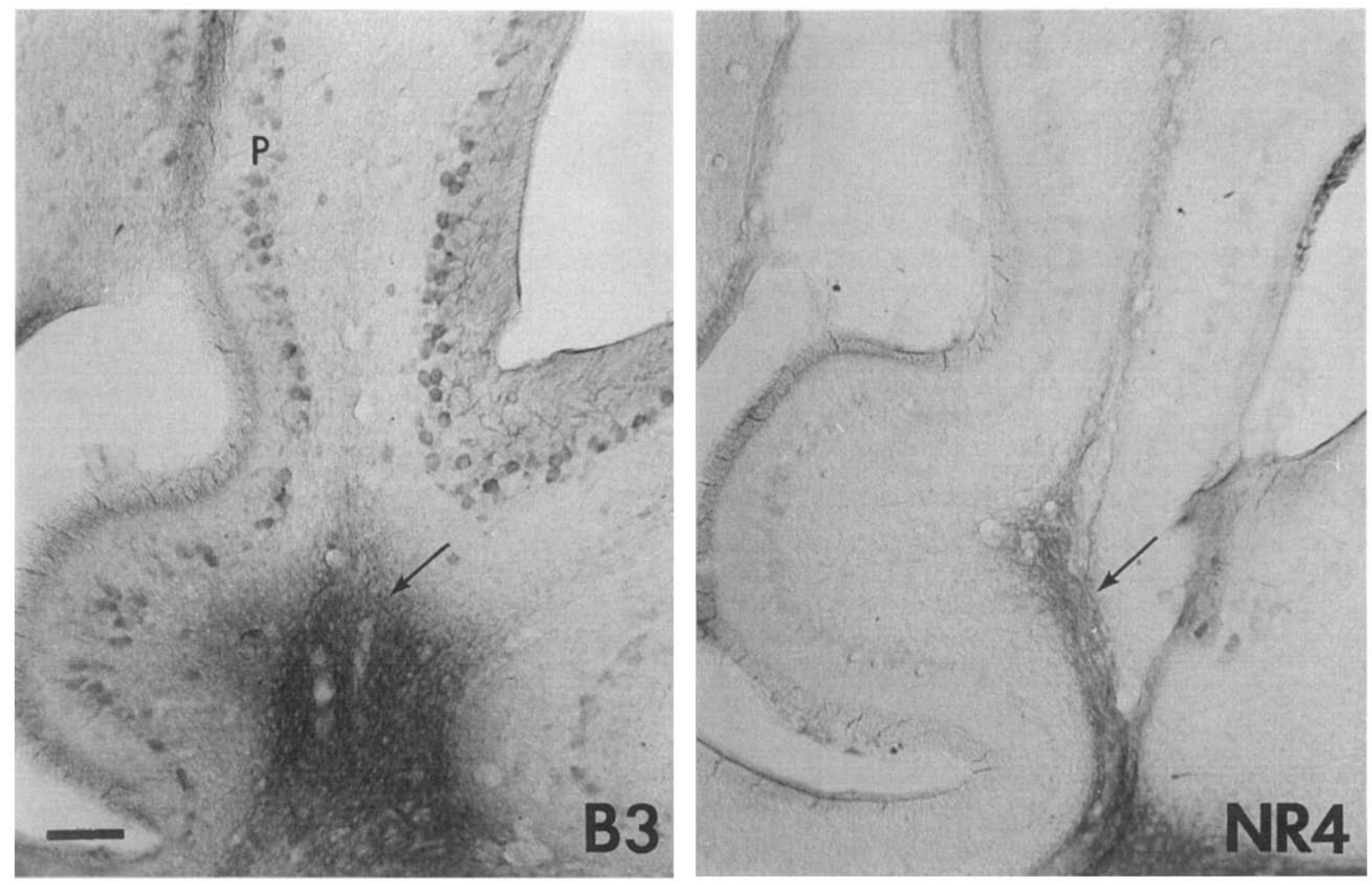

Fig. 5. B3 and NR4 neurofilament epitopes in the cerebellum of a 10-day-old rat. As in the cerebral cortex, both epitopes can be detected in axonal fibers of the cerebellar white matter (arrows). In addition, the B3 epitope is present in cell bodies and dendrites of the developing Purkinje cells $(P)$. Note the absence of basket cell axons at this stage. Bar $=0.1 \mathrm{~mm}$.

tivity with cell bodies or dendrites of differentiating cortical cells, although axonal fibers in the cortical white matter were equally well labelled by both antibodies. During subsequent cortical development, the presence of the NR4 epitope in neuronal cell bodies gradually increased, while the abundance of the B3 and A1 epitopes generally declined.

In the 10-day-old rat cerebellum, dendrites of the Purkinje cells are differentiating, and only axons of climbing fibers in the white matter are present (Fig. 5). At this stage, B3-labelled cell bodies and dendritic trees of Purkinje cells, as well as climbing fiber axons are seen. NR4 stained the Purkinje cell bodies weakly, but it labelled the axons in the cerebellar white matter as strongly as those in the cortical white matter.

In adult rats on the other hand, the presence of the B3 epitope was markedly reduced, and largely restricted to cell bodies and larger dendrites (Fig. 6; cortex). The degree of immunoreactivity in fiber systems was somewhat variable in different regions with our mabs; but on the whole, large fiber systems, such as corpus callosum, fornix, and striatal tracts, were stained moderately by $\mathrm{B} 3$ and poorly by A1. NR4, in contrast, strongly detected the fine dendritic processes of cortical neurons. Fiber tracts also displayed a very prominent stain with NR4.

In the adult cerebellum, the B3 epitope could be demonstrated in cell bodies and larger dendrites of the Purkinje cells (Fig. 7). B3 and A1 staining of axonal arborizations in the adult cerebellum was moderate, as in the basket cell terminals around the Purkinje cell bodies, or weak, as in the cerebellar white matter. In contrast, these axonal structures were the prominent features of the NR4 staining pattern. NR4 did not label the cell bodies and dendrites of the Purkinje cells.

The differences in staining pattern that we detected did not seem to be restricted to one species: in brain sections of adult cats and macaque monkeys, 

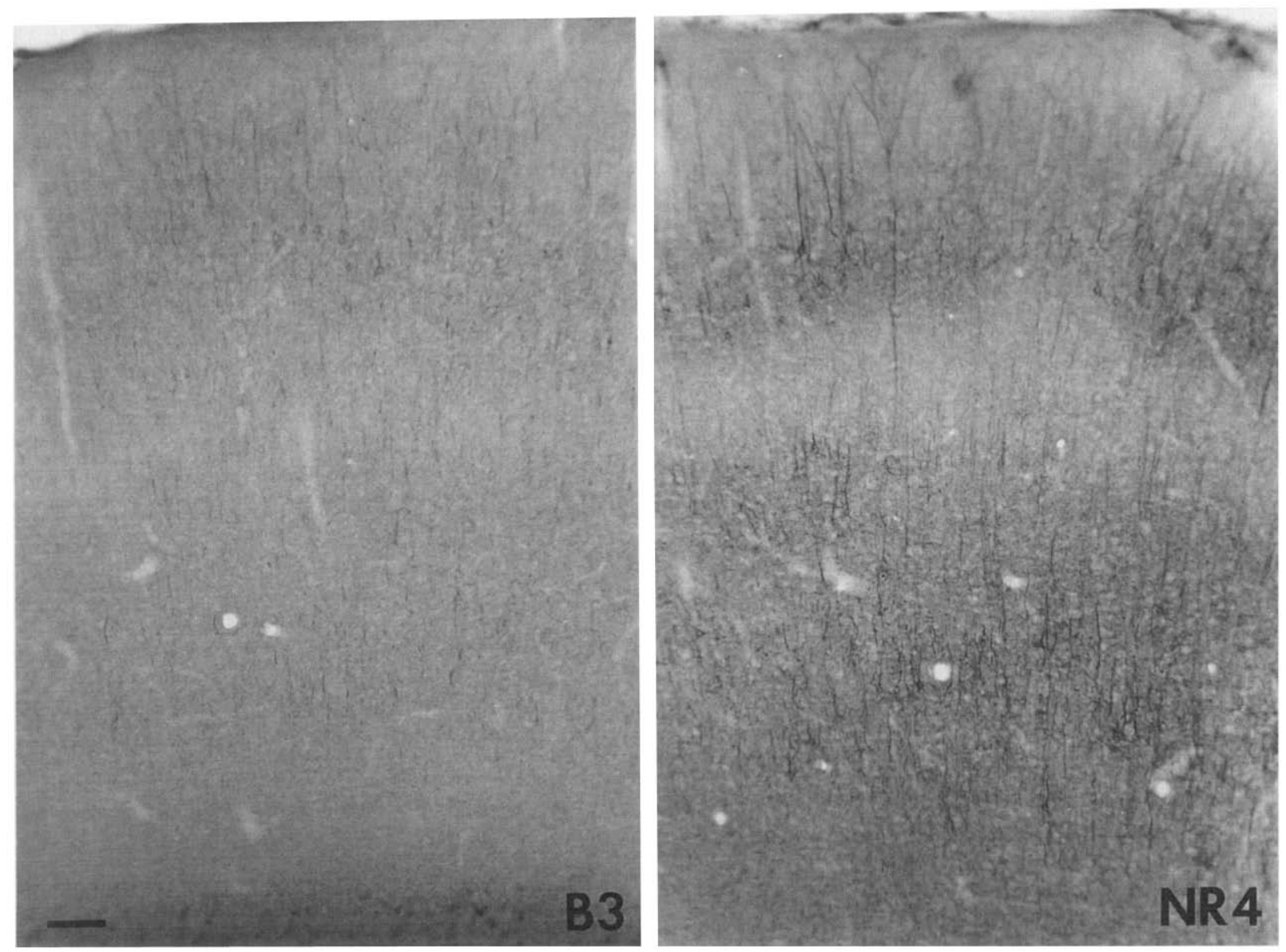

Fig. 6. B3 and NR4 neurofilament epitopes in the cerebral cortex of an adult rat. The NR4 epitope is detectable along multiple small dendritic arborizations of cortical neurons, whereas the B3 epitope is scarce and does not extend beyond the primary dendrites. Bar $=0.1 \mathrm{~mm}$

differences in immunoreactivity of cell bodies and axonal structures identical to those in rat brain were observed. However, we did not have the opportunity to investigate developing brain of these species. Fig. 8 shows sections through motor cortex of Macaca fascicularis where differences in the subcellular distribution of epitopes are even more clearly demonstrated than in rat brain. Restriction of the B3 stain to proximal dendrites and cell bodies is visible in the extraordinarily large pyramidal neurons of layer V. NR4, on the other hand, recognized a multitude of fine neurofibrils in dendrites and axons, whereas in the cell bodies the NR4 stain seemed to be concentrated in a submembraneous rim.

When cell cultures from rat cerebral cortex or hippocampus as in vitro systems of differentiation were examined, staining of neurons 3-4 days in culture was frequently observed with our antibodies (See Fig. 1). Under the same conditions, a delayed appearance of NR4 epitopes (only after 7 days or more in vitro) was noted; the observed abundance was low and was predominantly located in the axons of only a few cells (data not shown; comparable findings in ref. 42 ).

In all immunohistochemical experiments, parallel stains for the other two intermediate filaments present in brain, vimentin and GFAP, were performed. The tissue distribution of these antigens showed no overlap with our neurofilament epitopes at any of the ages we investigated. Thus, we can exclude any cross-reactivities of our antibodies with other intermediate filaments in tissue stains.

Fig. 9 is a schematic representation of a comparison between the subcellular distribution of the 

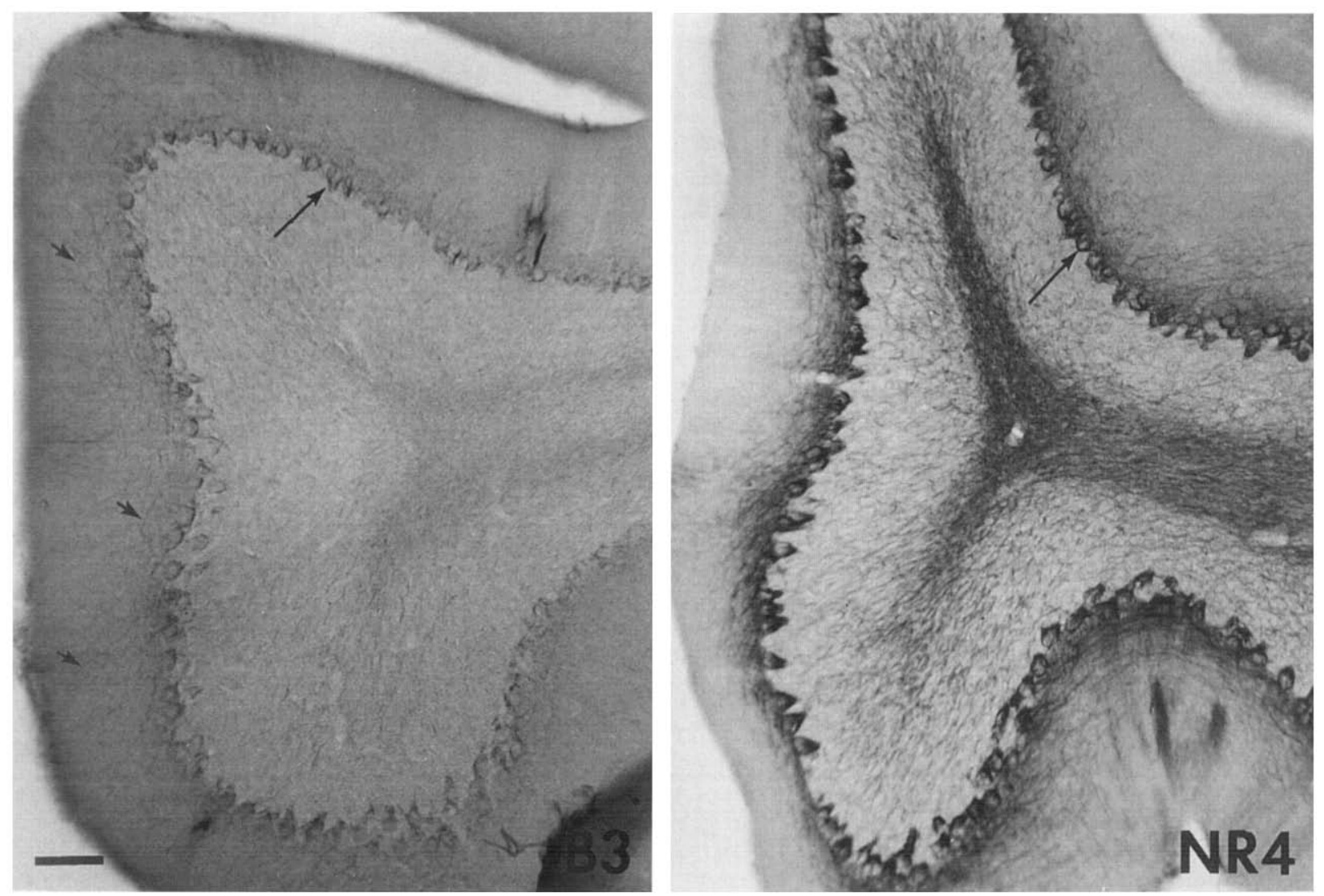

Fig. 7. B3 and NR4 neurofilament epitopes in the cerebellum of an adult rat. Only the B3 epitope is present in the dendritic trees of the Purkinje neurons. In addition to immunoreactive larger dendrites (small arrows), the cerebellar molecular layer displays a general stain. The distribution of the B3 epitope in axons is differential: it is present in basket cell axons around the Purkinje cell bodies (long arrows), but scarce in the fibers of the white matter. The NR4 epitope is present in the two axonal systems only. Bar $=0.1 \mathrm{~mm}$.

epitopes recognized by our mabs and by NR4 in a differentiating cortical pyramidal cell and in a mature cortical neuron.

After establishing a significant difference in the distribution of the neurofilament epitopes recognized by our antibodies and NR4, we then wanted to show these different epitope specificities in immunoblots as well. However, we were unable to detect any significant differences in the developmental time course of immunoreactivity. This is demonstrated in Fig. 10 for forebrain homogenates from rats aged embryonic day 18 to postnatal day 21 . On Western blots, both with our antibody and with NR4, the first NF-L proteins were detected at around postnatal day 3-5; their abundance then increases gradually, until it reaches a steady state when neuronal differentiation is completed at the end of the second postnatal week. Western blot analysis did not show a reduction in neurofilament proteins recognized by our antibodies after the first postnatal week, in contrast to the reduction in neurofilament staining in adult rat and monkey brain.

The possibility that this unexpected result was due to our antibodies recognizing a different protein after aldehyde fixation was excluded by fixing immunoblots with paraformaldehyde before reacting them with the antibodies: both A1 and B3 still recognized the $68 \mathrm{kDa}$ protein, and only this band, after aldehyde fixation. Thus, we conclude that the mabs recognize an epitope on the $68 \mathrm{kDa}$ neurofilament protein in immunoblots and in some neurofibrils in tissue sections, but in other neurofibrils the epitope obviously becomes unavailable for antibody binding. 

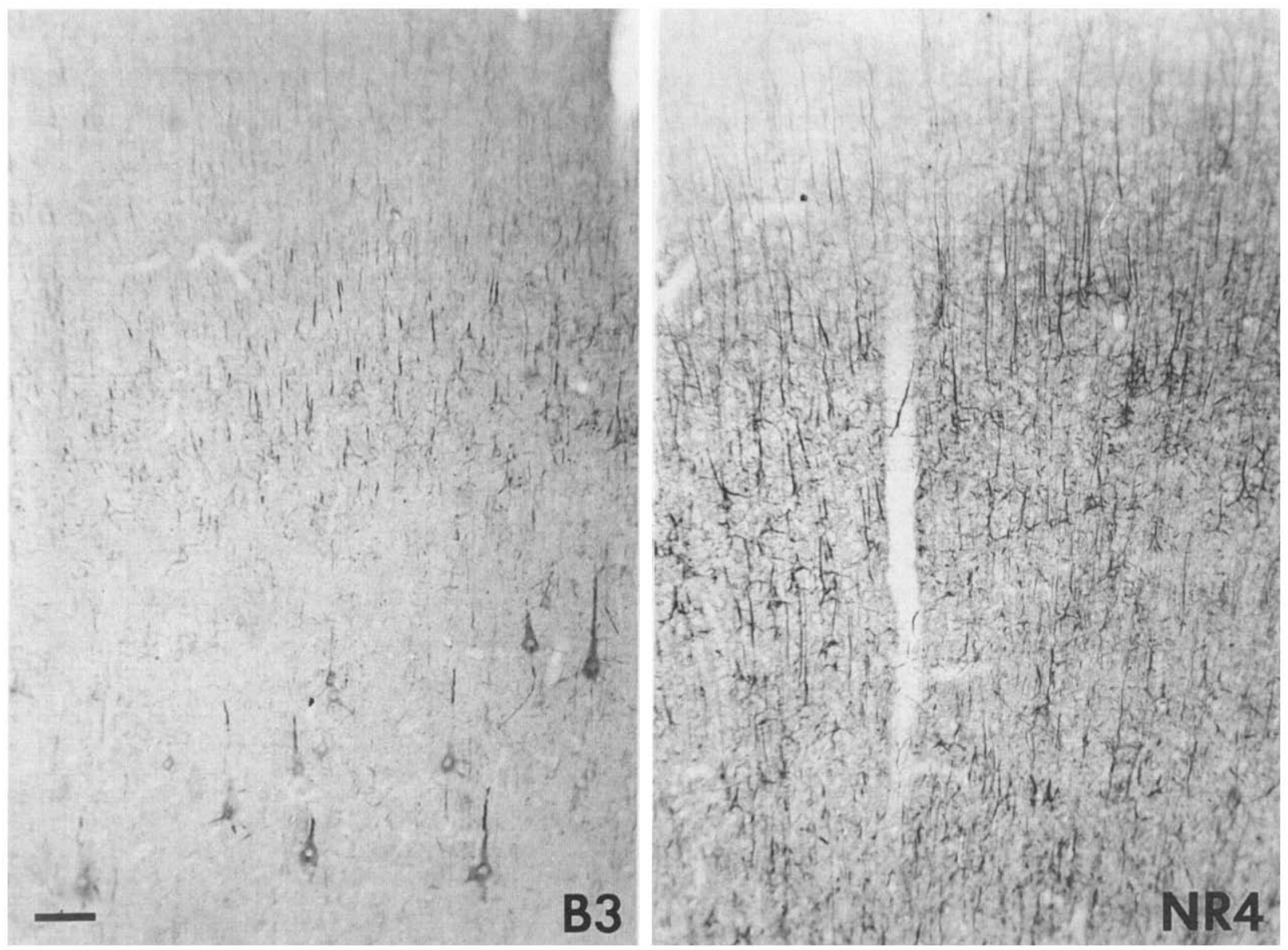

Fig. 8. B3 and NR4 neurofilament epitopes in motor cortex of adult macaque monkey (Macaca fascicularis). The restriction of the B3 epitope to cell bodies and the proximal part of the apical dendrites is particularly well visible in the large layer $V$ pyramidal cells in the bottom half of the figure. As in adult rat cortex, the NR4 epitope extends into a large number of fine dendritic processes. $\mathrm{Bar}=0.1 \mathrm{~mm}$.

\section{DISCUSSION}

In this paper we report differential regulation of antigenic sites on the small neurofilament protein, NF- $\mathrm{L}$, in development and in subcellular compartments. The biochemical nature of the developmentally regulated modification is as yet unknown to us, but a clue comes from the fact that it can be observed only in tissue sections after paraformaldehyde fixation.

The developmental time course we see with our antibodies in immunoblots coincides with the time course of neurofilament expression as has been described in the literature: in chick, NF-L is first detected anytime between the last mitosis of the neuronal precursors and the end of their migration, depending upon neuronal type ${ }^{4}$. In rats, NF-L is expressed de novo in terminally differentiated nerve cells, coincident with the initial axonal extension; it gradually replaces the vimentin present in mitotic neuroepithelial cells ${ }^{9.29 .46}$. For example, it is present in the ganglion cells of rat retina from embryonic day 15.5 on, in retinal horizontal cells after birth concomitant with the formation of layers ${ }^{41}$, and in rat optic nerve from embryonic day $15 \mathrm{on}^{14}$.

Thus, the overall concentration of neurofilaments in the brain increases gradually following neuron production $^{8}$, until a terminal level is attained upon maturation of neuronal pathways. In SDS-polyacrylamide gels of rat brain intermediate filament preparations, NF-L could be detected as early as embryonic day 20 (ref. 40 ). 

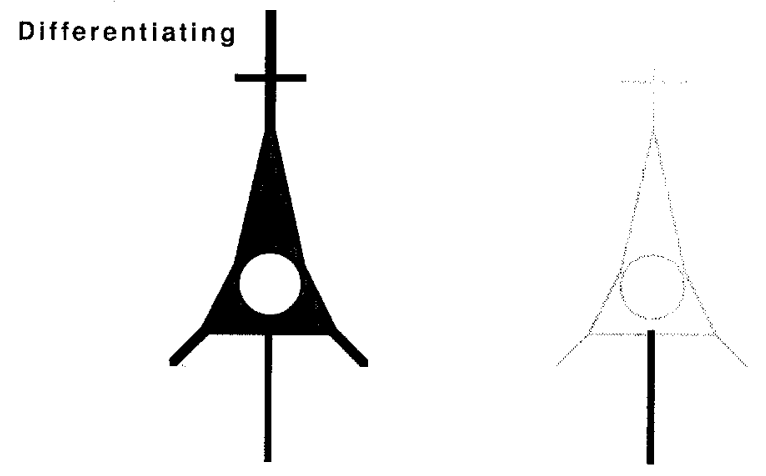

Adult

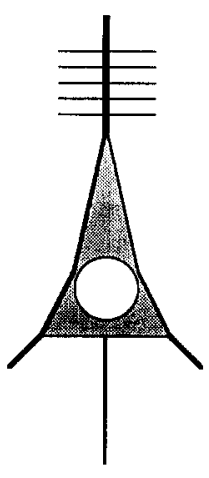

A 1/B 3

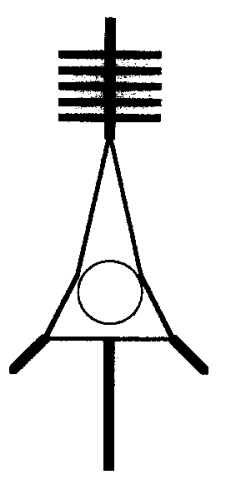

NR4
Fig. 9. Subcellular distribution of A1/B3 and NR4 neurofilament epitopes during differentiation and in the mature state is summarized in a schematized drawing of a cortical pyramidal neuron. During neuronal differentiation A1 and B3 epitopes are abundant in all parts of the cell, while the NR4 epitope is restricted to its axon. In adult neurons, the abundance of $\mathrm{A} 1$ and B3 epitopes generally decreases; it decreases more in axons and distal dendrites than in the cell body and the primary dendrites. The NR4 epitope is abundant in all parts of adult neurons, except in the inner regions of the cell body.

The time course of NF-L expression in forebrain homogenates, as detected with B3 and NR4, coincides well with the time of cortical layer formation. On the other hand, the developmental and subcellular distribution pattern observed in the tissue in situ with either our antibodies or the NR4 antibody can account for only a fraction of the existing $68 \mathrm{kDa}$ neurofilament proteins, as the mabs obviously stain partially overlapping sets of neurofibrils. Thus, we conclude that the antibodies recognize epitopes that are inaccessible in some filaments in situ, and remain inaccessible during our relatively mild perfusion conditions, which leave 3-dimensional structures intact. Upon stronger denaturation of the protein,

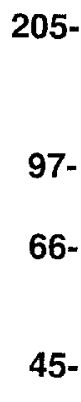

205-
$97-$
$66-$
$45-$

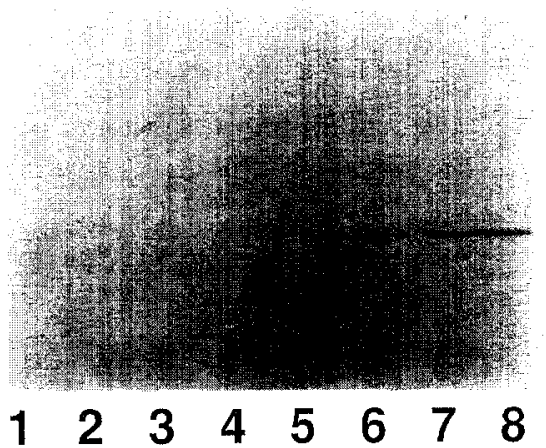

B3

205-

NR4

97-

66-

45-

\section{$\begin{array}{llllllll}1 & 2 & 3 & 4 & 5 & 6 & 7 & 8\end{array}$}

Fig. 10. Developmental profile of B3 and NR4 epitopes in immunoblots of SDS-polyacrylamide gels. Forebrain homogenates ( $50 \mu \mathrm{g}$ protein per lane) were prepared from rats of different ages: lane 1, day 18 of gestation; lane 2, newborn; lane 3, 3 days old; lane 4, 5 days old; lane 5, 7 days old; lane 6, 10 days old; lane 7,14 days old; and lane 8,21 days old. Both epitopes are first detectable at 3-5 days after birth, and gradually increase in abundance towards a steady state which is reached after the second postnatal week. No specific differences can be detected between the developmental profiles of B3 and NR4.

e.g. after treatment with SDS and reducing agents, the epitopes become exposed to antibody binding.

In addition to our immunoblot data, the following indirect evidence makes it unlikely that our antibodies detect a specific phosphorylation state of NF-L, similar to the phosphorylation-dependent epitopes on NF-H and NF-M: (1) NF-L has only a few phosphate groups which are probably on its $\alpha$-helical core $^{7,27}$. In contrast, the immunogenic, differentially distributed phosphate groups of NF-H and NF-M are located on their $\mathrm{COOH}$-terminal tails ${ }^{7,24,26,27,36}$.

$E$. coli alkaline phosphatase removes more than $90 \%$ of the phosphate groups from NF-H and NF-M but only $10 \%$ of the phosphate groups from NF-L, suggesting a stable in vivo phosphorylation state for NF- $\mathrm{L}^{7}$. As a consequence, it is difficult to reveal 
phosphorylation-dependent epitopes on NF-L by enzymatic dephosphorylation ${ }^{7,27,43}$.

However, there are several other possible explanations for the observed preferences of our antibodies:

(1) Our antibodies distinguish between isoforms that are modified post-translationally other than by phosphorylation. To explain the results, we would have to postulate that our antibodies fail to recognize a certain modification which would have to be labile to denaturation or reduction by the SDS sample buffer. For instance, our epitopes might be destroyed by formation of disulfide bonds between NF-L molecules. Evidence for a dimeric structure is reported for NF-L, as well as for other intermediate filaments under non-reducing conditions ${ }^{19}$; and sedimentation studies undertaken to understand the arrangement of the polypeptide chains even suggest a tetrameric structure of NF-L in aqueous solution ${ }^{10}$.

(2) Our antibodies recognize an epitope which becomes masked and unmasked as the quaternary structure of the filament changes with its functional state. There are examples for masking of epitopes on intermediate filaments. Most of them occur generally, though, independent of the developmental stage of the cell. For instance, antibodies that recognize GFAP core domain epitopes stain this protein in immunoblots but fail to react with their antigen in tissue ${ }^{12}$; and there is an early report of an NF-L antiserum that stains only in immunoblots, and not in formaldehyde-fixed tissue sections or cell cultures ${ }^{1}$.

In a few cases antibodies recognized epitopes that were masked and unmasked with the functional state of the cytoskeleton, e.g. an epitope on glial filaments was masked in certain phases of the cell cycle ${ }^{16}$. Antigenic sites on NF-M and NF-H were accessible on blots but not in aldehyde-fixed tissue sections of neonatal retina and 7-day cerebellum, although they were detected in adult sections ${ }^{22}$. An intriguing possibility is that the conformational change to which our antibodies are sensitive is induced by the phosphorylation of NF-H. This molecule, as well as NF-M, is known to undergo strong conformational changes upon phosphorylation resulting in a considerably higher apparent molecular weight for the phosphorylated form in electrophoresis?. It is thought that phosphorylation stabilizes compacted forms of neurofilaments with specific functions ${ }^{45}$. Moreover, the existence of early, immature neurofilament forms containing NF-L and NF-M is postulated $^{x}$. Loss of an antigenic site subsequent to the late phosphorylation of NF-H might explain some of the staining patterns of our antibodies.

(3) Our antibodies recognize a binding site for another molecule on NF-L, e.g. in some functional states the epitope is masked by the ligand. For NF-L, binding interactions with a variety of proteins are suggested: a binding site has been postulated for brain spectrin in the $\mathrm{N}$-terminal head region of the molecule $^{18}$, and another one for synapsin I with a binding ratio of 1:1 (ref. 44). MAP2 and tau-protein were found to bind with a calculated ratio of $1: 30$ and $1: 3$, respectively, to the core domain ${ }^{32}$; interaction of the latter with our epitopes could explain some of our results, as tau is axon-specific.

Furthermore, binding of NF-L or its degradation products to single-stranded RNA and DNA is reported and postulated to be one step of a hypothesized feedback regulation ${ }^{50}$. As a last possibility, neurofilaments may interact with each other by binding of the carboxy-terminal ends of the high molecular weight NF proteins to the NF-L core of another filament, as is suggested by gelation studies of native neurofilaments ${ }^{2 x}$.

In summary, our findings suggest an epitope on NF- $L$ whose presence is regulated depending on the functional state of the neurofilament, either by means of post-translational modifications, by a differential build-up of the filament, or by binding of a ligand to the $68 \mathrm{kDa}$ neurofilament protein. Our results show that monoclonal antibodies, by virtue of their high specificity, are sensitive probes for small protein modifications and heterogeneities that cannot easily be detected by analytical methods alone.

\section{ACKNOWLEDGEMENTS}

We would like to thank Dr. Astrid Zimmermann and Dr. Arne Sutter for instruction in the monoclonal antibody technique and the opportunity for I.T. to work in their laboratory; B. Scheufler and U. Rexhausen for excellent technical assistance; Dr. G. Shaw for his generous gift of neurofilament antiserum; Dr. O. Creutzfeldt for his support of this work; 
and Dr. M. Osborn for helpful discussions and generous supply of NR4 monoclonal antibody. This

\section{REFERENCES}

1 Anderton, B.H., Thorpe, R., Cohen, J., Selvendran, S. and Woodhams, P., Specific neuronal localization by immunofluorescence of $10 \mathrm{~nm}$ filament polypeptides, $J$. Neurocytol., 9 (1980) 835-844.

2 Aoki, C. and Siekevitz, P., Ontogenetic changes in the cyclic adenosine $3^{\prime}, 5^{\prime}$-monophosphate-stimulatable phosphorylation of cat visual cortex proteins, particularly of microtubule-associated protein 2 (MAP2): effects of normal and dark rearing and of the exposure to light, $J$. Neurosci., 5 (1985) 2465-2483.

3 Banker, G.A. and Cowan, W.M., Rat hippocampal neurons in dispersed cell culture, Brain Res., 126 (1977) $397-425$.

4 Bennett, G.S. and DiLullo, C., Expression of a neurofilament protein by the precursors of a subpopulation of ventral spinal cord neurons, Dev. Biol., 107 (1985) 94-106.

5 Bignami, A., Chi, N.H. and Dahl, D., Neurofilament phosphorylation in peripheral nerve regeneration, Brain Res., 375 (1986) 73-82.

6 Bottenstein, J.E. and Sato, G.H., Growth of a rat neuroblastoma cell line in serum-free hormone supplemented medium, Proc. Natl. Acad. Sci. U.S.A., 76 (1979) 514-517.

7 Carden, M.J., Schlaepfer, W.W. and Lee, V.M., The structure, biochemical properties, and immunogenicity of neurofilament peripheral regions are determined by phosphorylation state, J. Biol. Chem., 260 (1985) 9805-9817.

8 Carden, M.J., Trojanowski, J.Q., Schlaepfer, W.W. and Lee, V.M., Two-stage expression of neurofilament polypeptides during rat neurogenesis with early establishment of adult phosphorylation, J. Neurosci., 7 (1987) 3489-3504.

9 Cochard, P. and Paulin, D., Initial expression of neurofilaments and vimentin in the central and peripheral nervous system of the mouse embryo in vivo, J. Neurosci., 4 (1984) 2080-2094.

10 Cohlberg, J.A., Hajarian, H. and Sainte-Marie, S., Discrete soluble forms of middle and high molecular weight neurofilament proteins in dilute aqueous buffers, Proc. Nall. Acad. Sci. U.S.A., 262 (1987) 17009-17015.

11 Cole, G.J., Bond, R. and Glaser, L., Monoclonal antibodies specific for ganglion cells in the embryonic chicken neural retina, Dev. Brain Res., 26 (1986) 133-143.

12 Dahl, D., Grossi, M. and Bignami, A., Masking of epitopes in tissue sections. A study of glial fibrillary acidic (GFA) protein with antisera and monoclonal antibodies, Histochemistry, 81 (1984) 525-531.

13 Dahl, D. and Bignami, A., Neurofilament phosphorylation in development. A sign of axonal maturation?, Exp. Cell Res., 162 (1986) 220-230.

14 Dahl, D., Crosby, C.J., Gardner, E.E. and Bignami, A., Delayed phosphorylation of the largest neurofilament protein in rat optic nerve development, $J$. Neurosci. Res., 15 (1986) 513-519.

15 DeCamilli, P., Miller, P.E., Navone, F., Theurkauf, W.E. and Vallee, R.B., Distribution of microtubule-associated protein 2 in the nervous system of the rat studied by immunofluorescence, Neuroscience, 11 (1984) 819-846. work was financially supported by the Stiftung Volkswagenwerk which is gratefully acknowledged.

16 Debus, E., Weber, K. and Osborn, M., Monoclonal antibodies specific for glial fibrillary acidic (GFA) protein and for each of the neurofilament triplet polypeptides. Differentiation, 25 (1983) 193-203.

17 Franke, W.W., Schiller. D.L., Moll, R., Winter, S., Schmid, E. and Engelbrecht, I.. Diversity of cytokeratins. Differentiation specific expression of cytokeratin polypeptides in epithelial cells and tissues, J. Mol. Biol., 153 (1981) 933-959.

18 Frappier, T., Regnouf, F. and Pradel, L.A., Binding of brain spectrin to the $70-\mathrm{kDa}$ neurofilament subunit protein, Eur. J. Biochem., 169 (1987) 651-657.

19 Gardner, E.E., Rueger, D.C. and Dahl, D., The relationship of bovine intermediate filament proteins. A comparative analysis of glial fibrillary acidic protein, desmin and the neurofilament $70 \mathrm{kDa}$ protein, Biochim. Biophys. Acta, 790 (1984) 141-147.

20 Glicksman, M.A. and Willard, M., Differential expression of the three neurofilament polypeptides, Ann. N.Y. Acad. Sci., 455 (1985) 479-491.

21 Goldstein, M.E., Sternberger, L.A. and Sternberger, N.H., Microheterogeneity ('neurotypy') of neurofilament proteins, Proc. Natl. Acad. Sci. U.S.A., 80 (1983) 31013105 .

22 Hofstein, R., Majocha, R.E., Barnstable, C.J. and Marotta, C.A., Non-uniform distribution of neurofilament epitopes in the CNS during development, Ann. N.Y. Acad. Sci., 455 (1985) 787-789.

23 Jacobson, R.D., Virag, I. and Skene, J.H.P., A protein associated with axon growth, GAP-43, is widely distributed and developmentally regulated in rat CNS, J. Neurosci, 6 (1986) 1843-1855.

24 Julien, J.-P. and Mushynski, W.E., Multiple phosphorylation sites in mammalian neurofilament polypeptides, $J$. Biol. Chem., 257 (1982) 10467-10470.

25 Laemmli, U.K., Cleavage of structural proteins during the assembly of the head of bacteriophage T4, Nature (Lond.), 227 (1970) 680-685.

26 Lee, V.M., Carden, M.J. and Trojanowski, J.Q., Novel monoclonal antibodies provide evidence for the in situ existence of a non-phosphorylated form of the largest neurofilament subunit, J. Neurosci, 6 (1986) 850-858.

27 Lee, V.M., Carden, M.J. and Schlaepfer, W.W., Structural similarities and differences between neurofilament proteins from five different species as revealed using monoclonal antibodies, J. Neurosci., 6 (1986) 2179-2186.

28 Leterrier, J.-F. and Eyer, J., Properties of highly viscous gels formed by neurofilaments in vitro, Biochem. J., 245 (1987) 93-101.

29 Lewis, S.A. and Cowan, N.J., Genetics, evolution, and expression of the 68,000 -mol-wt neurofilament protein: isolation of a cloned cDNA probe, J. Cell Biol., 100 (1985) 843-850.

30 Luben, R.A. and Mohler, M.A., In vitro immunization as an adjunct to the production of hybridomas producing antibodies against the lymphokine osteoclast activating factor, Mol. Immunol., 17 (1980) 635-639.

31 Matus, A., Huber, G, and Bernhardt, R., Neuronal microdifferentiation, Cold Spring Harbor Symp. Quant. 
Biol., 48 (1983) 775-782.

32 Miyata, Y., Hoshi, M., Nishida, E., Minami, Y. and Sakai, H., Binding of microtubule-associated protein 2 and tau to the intermediate filament reassembled from neurofilament 70-kDa subunit protein, J. Biol. Chem., 261 (1986) 13026-13030.

33 Moskal, J.R. and Schaffner, A.E., Monoclonal antibodies to the dentate gyrus: immunocytochemical characterization and flow cytometric analysis of hippocampal neurons bearing a unique cell-surface antigen, J. Neurosci., 6 (1986) 2045-2053

34 Müller, H.W., Beckh, S. and Seifert, W., Neurotrophic factor for central neurons, Proc. Natl. Acad. Sci. U.S.A., 81 (1984) $1248-1252$.

35 Oblinger, M., Characterization of posttranslational processing of the mammalian high-molecular-weight neurofilament protein in vivo, $J$. Neurosci., 7 (1987) 2510-2521.

36 Peng. I., Binder, L.I. and Black, M.M., Biochemical and immunological analyses of cytoskeletal domains of neurons, J. Cell Biol., 102 (1986) 252-262.

37 Peterson. G.L., A simplification of the protein assay method of Lowry et al. which is more generally applicable, Anal. Biochem., 83 (1977) 346-356.

38 Pigott. R. and Kelly, J.S., A cell surface antigen present on cultured cerebellar neurones appears to be transiently expressed during cerebellar development in the rat, $\mathrm{Neu}$ rosci. Lett., 49 (1984) 105-110.

39 Shaw, G. and Weber, K.. The distribution of the neurofilament triplet proteins within individual neurones, Exp. Cell Res., 136 (1981) 119-125.

40) Shaw, G. and Weber, K.. Differential expression of neurofilament triplet proteins in brain development, $\mathrm{Na}$ ture (Lond.), 298 (1982) 277-279.

41 Shaw, G. and Weber, K., The structure and development of the rat retina: an immunofluorescence microscopical study using antibodies specific for intermediate filament proteins. Eur. J. Cell Biol., 30 (1983) 219-232.

42 Shaw, G., Banker, G.A. and Weber, K., An immunofluorescence study of neurofilament protein expression by developing hippocampal neurons in tissue culture, Eur. $j$. Cell Biol., 39 (1985) 205-216.

43 Shaw, G., Osborn, M. and Weber, K., Reactivity of a panel of neurofilament antibodies on phosphorylated and dephosphorylated neurofilaments, Eur. J. Cell Biol., 42 (1986) $1-9$

44 Steiner, J.P., Ling, E. and Bennett, V., Nearest neighbor analysis for brain synapsin. I. Evidence from in vitro reassociation assays for association with membrane proteins and the $M_{1} 68000$ neurofilament subunit, J. Biol. Chem., 262 (1987) 905-914.

45 Sternberger, L.A. and Sternberger, N.H., Monoclonal antibodies distinguish phosphorylated and nonphosphorylated forms of neurofilaments in situ. Proc. Natl. Acad. Sci. U.S.A., 80 (1983) 6126-6130.

46 Tapscott, S.J., Bennett, G.S., Toyama, Y., Kleinbart, F. and Holtzer, H., Intermediate filament proteins in the developing chick spinal cord, Dev. Biol., 86 (1981) 40-54.

47 Towbin. H., Staehelin, T. and Gordon, J., Electrophoretic transfer of proteins from polyacrylamide gels to nitrocellulose sheets: procedure and some applications, Proc. Natl. Acad. Sci. U.S.A., 76 (1979) 4350-4354.

48 Toyoshima, I., Satake, M. and Miyatake, T., Differences in the neurofilament proteins between the perikaryon and axon of the bovine spinal ganglion, Biomed. Res., 5 (1984) $459-464$.

49 Toyoshima, 1.. Yamamotu, A.. Satake, M. and Miyatake, T., Perikaryal proteins that react with an antibody against the $220 \mathrm{~K}$ component of axonal neurofilaments, Biomed. Res., 6 (1985) 339-342.

50) Traub, P., Vorgias, C.E. and Nelson, W.J.. Interaction in vitro of the neurofilament triplet proteins from porcine spinal cord with natural RNA and DNA, Mol. Biol. Rep., 10 (1985) 129-136.

51 Trojanowski. J.Q., Obrocka, M.A. and Lee, V.M., Distribution of neurofilament subunits in neurons and neuronal processes: immunohistochemical studies of bovine cerebellum with subunit-specific monoclonal antibodies, $J$. Histochem. Cytochem., 33 (1985) 557-563.

52 Vitadello, M., Triban, C., Fabris, M., Gorio, A. and Schiaffino, S., Heterogeneity of rat neurofilament polypeptides revealed by a monoclonal antibody. J. Neurochem., 46 (1986) 665-670.

53 Weisenberg, R.C., Microtubule formation in vitro in solutions containing low calcium concentrations. Science, 177 (1972) $1104-1105$ 